\title{
A study of swallowing difficulties in first degree relatives of patients with achalasia
}

\author{
JOHN F MAYBERRY, MICHAEL ATKINSON \\ From the University Hospital, Queen's Medical Centre, Nottingham
}

ABSTRACT Of 167 patients with achalasia asked to provide details of swallowing difficulties among their first degree relatives, 159 completed the survey (95\% response rate). One thousand and twelve first degree relatives were identified, and 14 were reported to have dysphagia including two with reported achalasia. Review of the case notes of these 14 relatives showed, however, that in none was achalasia confirmed. Heartburn affected $54(5 \%)$ of the relatives, an incidence similar to that in the general population. These findings suggest that adult achalasia is not inherited in an autosomal recessive manner and that environmental factors during early life do not play an important aetiological part.

The cause of achalasia remains obscure, but genetic inheritance by an autosomal recessive mechanism has been suggested.1-s Various environmental agents have been proposed as possible causes and include bacteria, ${ }^{67}$ viruses, ${ }^{8}$ toxic agents, ${ }^{9}$ and ischaemia in utero. ${ }^{10}$

This study was undertaken to determine the possible role of genetic inheritance in adult achalasia and to look for evidence of environmental influences as patients often share a similar background to their siblings.

\section{Patients and methods}

Achalasia is an uncommon disease, and our patients were identified from three sources: 20 were residents of Cardiff, 46 were from Nottingham, and 101 were referred to Nottingham from other areas. In all cases the diagnosis of achalasia was accepted only if one of the following criteria had been fulfilled:

(1) A barium swallow and meal result compatible with the diagnosis and an endoscopy that excluded an infiltrative carcinoma or a benign stricture.

(2) Absent or inconstant relaxation of the lower oesophageal sphincter as shown by manometry with associated absence of propagated peristaltic waves in the body of the oesophagus.

One hundred and sixty seven patients were sent a

Address for reprint requests: Professor $M$ Atkinson, University Hospital, Queen's Medical Centre, Nottingham NG7 2UH.

Accepted 12 December 1984 postal questionnaire about the occurrence of achalasia. This technique had already been validated in a study of Crohn's disease, ${ }^{11}$ and a sample questionnaire was tested by a medically qualified interviewer on a small group of patients with achalasia before mailing. The questionnaire recorded the occurrence of achalasia and difficulty in swallowing or heartburn in parents, siblings, and children of the patient with achalasia. The occurrence of these diseases in all first degree relatives, whether living or dead, was recorded. They were also asked whether any of these relatives had undergone radiography of the stomach (barium meal) at any time.

Details of family size, including numbers of brothers, sisters, and children, were also recorded. In those cases where a first degree relative was reported to have either achalasia or difficulty in swallowing details of the diagnosis were obtained, and if the patient had been investigated in hospital the clinical notes and radiographs were reviewed.

\section{Results}

Replies were received from 159 of the 167 patients contacted, which gave a response rate of $95 \%$ (table 1). Ninety three of the patients were women and 66 men. Median age at diagnosis was 48 (range 5-81) years. Data were not collected on the age of other family members. These 159 patients had 1012 first degree relatives, of whom 318 were parents, 248 brothers, 199 sisters, and 247 children. Fourteen relatives were reported to have difficulty in swallowing, including two with achalasia who had both died 
Table 1 Numbers of patients with achalasia and their relatives according to source

\begin{tabular}{|c|c|c|c|c|}
\hline & Cardiff & Nottingham & Nottingham referrals & Total \\
\hline $\begin{array}{l}\text { No of patients contacted } \\
\text { No of patients who replied } \\
\text { No of parents } \\
\text { No of siblings } \\
\text { No of children }\end{array}$ & $\begin{array}{l}20 \\
20 \\
40 \\
63 \\
45\end{array}$ & $\begin{array}{r}46 \\
41 \\
82 \\
152 \\
73\end{array}$ & $\begin{array}{r}101 \\
98 \\
196 \\
232 \\
129\end{array}$ & $\begin{array}{l}167 \\
159 \\
318 \\
447 \\
247\end{array}$ \\
\hline
\end{tabular}

Table 2 Swallowing problems among first degree relatives of patients with achalasia. (no relative had achalasia)

\begin{tabular}{lcrrr}
\hline & Parents & Siblings & Children & Total \\
\hline No of relatives & 318 & 447 & 247 & 1012 \\
No with dysphagia & 6 & 5 & 3 & 14 \\
No with heartburn & 38 & 11 & 5 & 54 \\
No who had a barium meal & 22 & 21 & 4 & 47 \\
\hline
\end{tabular}

(table 2). The first of the two patients with reported achalasia was the mother of a patient with the disorder and the second the father of another patient; both were investigated in hospital, and the first had been proved, by radiology and endoscopy, to have a hiatal hernia with oesophagitis, while the second had been shown to have a benign reflux stricture associated with a small hiatal hernia. In the 14 relatives with dysphagia only six had been investigated, with the following findings: two had duodenal ulceration alone, one a hiatal hernia, one a goitre, and one a mid-oesophageal squamous carcinoma; in the sixth dysphagia was the sequel to cerebrovascular disease. In the eight remaining dysphagic relatives an accurate diagnosis could not be obtained.

Heartburn affected 54 relatives (5\%), of whom 38 were parents, 11 siblings, and five children, but this corresponds with its prevalence in the general population. ${ }^{12}$

\section{Discussion}

Over 30 cases of familial incidence of achalasia have been reported, mostly in children. In many cases affected siblings have been the children of a consanguineous marriage, 4 and it has been suggested that the condition is inherited by an autosomal recessive mechanism with the genes being fully penetrant in the homozygous form. Only one report exists of achalasia in monozygotic twins ${ }^{13}$ and this emphasised that there was a long interval between the onset of symptoms in the first and the second twin. Although hereditary achalasia has been described in dogs, ${ }^{14}$ the body of the canine oesophagus contains only striated muscle and it therefore seems doubtful whether the condition is strictly comparable to achalasia in man.

Our findings indicate that the relatives of patients with achalasia are not at an increased risk of developing the disease. If, as has been suggested, achalasia were inherited as an autosomal recessive disease, Mendelian principles would predict up to 112 of the 447 siblings to be affected. It therefore seems highly improbable that achalasia in adults is inherited in such a manner, and our inability to trace any affected relatives suggests that inheritance is not normally an important aetiological factor. Aetiological environmental factors are, however, often shared by relatives, and the absence of the disease in any siblings in this series clearly points to an event occurring that is in most cases unique to the patient and is the specific cause of the disease. Future research on the aetiology of this condition must look for such a factor, which could be infective or toxicological.

\section{References}

1 Bosher P, Shaw A. Achalasia in siblings. Clinical and genetic aspects. Am J Dis Child 1981;135:709-10.

2 Westley CR, Herbst JJ, Goldman S, Wisek WC. Infantile achalasia: inherited as an autosomal recessive disorder. J Paediatr 1975;87:243-6.

3 Lowdon FA, Raab DE, Fuller J, Olsen A. Achalasia in three siblings. A rare occurrence. Mayo Clin Proc 1977;52:97-100.

4 Dayalan N, Chettur L, Ramakrishnan MS. Achalasia of the cardia in sibs. Arch Dis Child 1972;47:115-8.

5 Stoddart CJ, Johnson AG. Achalasia in siblings. Br J Surgery 1982;69:84-5.

6 Cameron JAM. Oesophagectasia in a child. Arch Dis Child 1927;2:358-60.

7 Cameron M. Suggested explanation of cardiospasm based on pathological changes. J Laryngol Otol 1928;43:218-20.

8 Muller B, Perron R, Gerest F, Giroux F. Un cas de mégaoesophage secondaire à une infection à virus neurotrope. Bulletin de la Societe Medicale des Hopitaux de Paris 1947;63:350-3.

9 Worms G, Leroux-Robert J. Les séquilles oesophagiennes des intoxications par le gas de combat. Contribution à l'étude pathogenique des grandes dila- 
tations de l'oesophage. Presse Medicale 1934;1:646-9.

10 Earlam RJ. Ischaemia: a hypothesis for the genesis of aganglionic bowel. (Isabella Forshell Prize Essay for Pediatric Surgery 1968.)

11 Mayberry JF, Rhodes J, Newcombe RG. Familial prevalence of inflammatory bowel disease in relatives of patients with Crohn's disease. Br Med J 1980;280:84.

12 Nebel OT, Fornes MS, Castell DO. Symptomatic gas- troesophageal reflux: incidence and precipitating factors. American Journal of Digestive Diseases 1976; 21:953-6.

13 Stein DT, Knauer CM. Achalasia in monozygotic twins. Dig Dis Sci 1982;27:636-40.

14 Osborne CA, Clifford DH, Jessen C. Hereditary oesophageal achalasia in dogs. J Am Vet Med Assoc 1967; 151:572-81.

\section{Book notices}

Mediastinal tumors and pseudotumors: diagnosis, pathology and surgical treatment. Istvan Besznyak, Bela Szende, Karoly Lapis. (Pp 336; \$77.25; S fr 129; DM 154.) Karger. 1984.

This book, printed in Hungary by Akedémiai Kiado, with the sole distribution rights in the non-socialist countries reserved by Karger, is the result of a close collaboration of a surgeon and two pathologists of international repute. The first two chapters cover anatomy of the mediastinum and the diagnosis of mediastinal space occupying lesions. The final chapter gives a good resumé of the surgical considerations in the treatment of mediastinal pathology. Each of the intervening eight chapters covers extensively the pathogenesis and pathology of individual groups of tumours, with short and succinct sections on surgical treatment. The authors state categorically that it was not their intention to discuss the place of radiotherapy or chemotherapy in the treatment of mediastinal pathology. That the wisdom of this policy is suspect is quite clear by the time the reader reaches the end of chapter 3 . The authors are to be congratulated on their attempt at simplifying the classification of thymic tumours, and in doing so indicating the clinical course of the respective groups. This book is well produced and readable. The pathological, histological, and ultrastructure illustrations are of a very high quality, but the same cannot be said of the radiological reproductions. No book on the mediastinum today should be published without examples of computed tomography illustrations and yet I failed to find a single example. A paragraph of three sentences is devoted to this entire subject, while several paragraphs (and a whole page of illustrations) are wasted on obsolete kymography. Each chapter is accompanied by a comprehensive list of references. Had the authors adopted the numerical system of citing references I would have found the pages far more captivating. There are several instances where whole paragraphs are devoted to listing references by authors and dates to qualify short statements. Despite these shortcomings, the chest physician and the surgical pathologist should find this book well worth reading. The practising thoracic surgeon should certainly recommend it for his departmental library, but at a price of $\$ 77.25$ it will meet with a lot of competition from other excellent contemporary publications in the same field.-KJ

Current therapy of respiratory disease 1984-1985. Reuben M Cherniack. (Pp 331; £38.) BC Decker Inc. 1984.

The purpose of this book is to present concise, up to date summaries of a comprehensive range of topics in respiratory medicine, emphasising recent advances in clinical science, diagnostic techniques, and therapeutic manoeuvres. By accepting the form of a yearbook in respiratory medicine, with regular revision, the editor seeks to reduce the "significant lag between the acquisition of new knowledge and its dissemination to practitioners." The book is divided into sections describing the upper respiratory tract, airways disease, parenchymal disorders, pulmonary vascular disease, pleural disease, lung cancer, and respiratory failure. The most enjoyable chapters (for example, $\alpha_{1}$ antitrypsin deficiency, pulmonary embolism, therapy of cor pulmonale, acute mountain sickness) are succinct, providing an expert review of areas of growing importance in the field, without preoccupation with minutiae. The value of the text as a whole would be enhanced by the inclusion of key references for further reading. The predominantly North American authorship devalues much of the therapeutics for British readers; there are striking differences in treatment regimens for tuberculosis and in the relative importance of $\beta_{2}$ agonists and xanthine derivatives in the management of bronchial asthma. Because of this emphasis on therapeutics, the value of the book for a British readership is limited.- RMC 